\title{
Model simulations of early westward flow across the Tasman Gateway during the early Eocene
}

\author{
Willem P. Sijp ${ }^{1}$, Anna S. von der Heydt ${ }^{2}$, and Peter K. Bijl ${ }^{3}$ \\ ${ }^{1}$ ARC Centre of Excellence for Climate System Science, University of New South Wales, Sydney, NSW 2052, Australia \\ ${ }^{2}$ Institute for Marine and Atmospheric Research, Centre for Extreme Matter and Emergent Phenomena, Utrecht University, \\ Princetonplein 5, 3584 CC Utrecht, the Netherlands \\ ${ }^{3}$ Marine Palynology and Paleoceanography, Laboratory of Palaeobotany and Palynology, Department of Earth Sciences, \\ Faculty of Geoscience, Utrecht University, P.O. Box 80115, 3508 TC Utrecht, the Netherlands
}

Correspondence to: Willem P. Sijp (w.sijp@unsw.edu.au)

Received: 10 July 2015 - Published in Clim. Past Discuss.: 29 October 2015

Revised: 17 February 2016 - Accepted: 6 March 2016 - Published: 5 April 2016

\begin{abstract}
The timing and role in ocean circulation and climate of the opening of Southern Ocean gateways is as yet elusive. Recent micropalaeontological studies suggest the onset of westward throughflow of surface waters from the SW Pacific into the Australo-Antarctic Gulf through a southern shallow opening of the Tasman Gateway from 49$50 \mathrm{Ma}$ onwards, a direction that is counter to the presentday eastward-flowing Antarctic Circumpolar Current. Here, we present the first model results specific to the early-tomiddle Eocene where, in agreement with the field evidence, southerly shallow opening of the Tasman Gateway indeed causes a westward flow across the Tasman Gateway. As a result, modelled estimates of dinoflagellate biogeography are in agreement with the recent findings. Crucially, in this situation where Australia is still situated far south and almost attached to Antarctica, the Drake Passage must be sufficiently restricted to allow the prevailing easterly wind pattern to set up this southerly restricted westward flow. In contrast, an open Drake Passage, up to $517 \mathrm{~m}$ deep, leads to an eastward flow, even when the Tasman Gateway and the AustraloAntarctic gulf are entirely contained within the latitudes of easterly wind.
\end{abstract}

\section{Introduction}

The different positions of large continents in the Southern Hemisphere influenced the oceanography of the Eocene and thus the distribution of heat. The position of Australia and
South America in the Eocene was much closer to Antarctica than today (see, e.g., Cande and Stock, 2004). This arguably prevented circumpolar surface water flow (Huber et al., 2004; Bijl et al., 2011, 2013), i.e. the Antarctic Circumpolar Current (ACC), that thermally isolates Antarctica today (Toggweiler and Bjornsson, 2000; Sijp and England, 2004). Instead, it was thought that low-latitude currents bathed Antarctic coastlines. The subsequent opening of a circumpolar passage, through deepening of the Drake Passage (DP) and Tasman Gateway (TG), would then allow the ACC to develop, leading to the isolation of Antarctica and progressive cooling, ultimately leading to full glaciation of Antarctica (Kennett, 1977). Support for this hypothesis came when it was discovered that the deep opening of these gateways appeared to be roughly coeval with the onset of continental-scale Antarctic glaciation around the EoceneOligocene transition (EOT; about 34 million years ago, Ma; Barrett, 1996).

Objections to the gateway hypothesis came from two fields of research. First of all, drill cores obtained from the Tasman Gateway region showed that accelerated widening and deepening of the passage likely started $2 \mathrm{Myr}$ prior to the glaciation, indicating that a direct causal link between the two is unlikely (Stickley et al., 2004). Unlike the quite precise estimates for the opening of the Tasman Gateway, the timing of the opening of the Drake Passage is debated and less well constrained (Barker and Burrell, 1977; Livermore et al., 2004; Scher and Martin, 2006; Pfuhl and McCave, 2005). Several structural geologic investigations in the re- 
gion have inferred crustal stretching from the early Eocene onwards (Lagabrielle et al., 2009; Ghiglione et al., 2008), but it remains unclear whether the vertical displacement of that tectonism caused a shallow passageway through the Drake Passage. We cannot, however, rule out the possibility that the Drake Passage was already open, but shallow, in the early Eocene.

Secondly, numerical modelling studies with general circulation models (GCMs) configured for the Eocene emerged that suggested an ocean circulation pattern with clockwise circulating gyres (Sloan et al., 1995; Huber and Sloan, 2001; Huber et al., 2004), where western boundary currents near Antarctica (as part of a subpolar gyre) still prevented lowlatitude currents from reaching and warming Antarctica (a general feature of subpolar gyres). Microfossil biogeography studies (notably, but not exclusively, done on organicwalled dinoflagellate cysts) clearly support the gyre configuration as suggested by numerical modelling experiments (Huber et al., 2004; Bijl et al., 2011) rather than the strong influence of low-latitude-derived ocean currents. It should be noted here that these considerations of the gyre circulation alone are centred on the surface circulation and do not include influences of thermohaline heat transport, which has been shown to have the potential to significantly enhance oceanic heat transport to Antarctica in a closed-gateway configuration (Sijp et al., 2009, 2011; Yang et al., 2013).

The existing proxy records for atmospheric $\mathrm{CO}_{2}$ during the Paleogene (Pagani et al., 2005; Pearson et al., 2009; Beerling and Royer, 2011) and ice sheet modelling (DeConto and Pollard, 2003; DeConto et al., 2008) have steered opinion in the direction of declining atmospheric greenhouse gas concentrations as the primary forcing factor in explaining Eocene cooling in general and, ultimately, the onset of continental-scale glaciation.

Although gateway changes appear not to be the direct cause of EOT glaciation, unlike the hypothesis first proposed by Kennett (1977) and Kennett and Shackleton (1976), their role in the general long-term Cenozoic cooling trend remains plausible (Stickley et al., 2004; Bijl et al., 2013; Sijp et al., 2014) but poorly reconciled with data. Indeed, glaciation (34 Ma) took place against the backdrop of a long and gradual cooling trend in the Southern Ocean (Bijl et al., 2009), whereas detailed geological reconstructions of the Tasman Gateway have, until recently (Bijl et al., 2013), largely ignored the potential climatic effects of earlier stages of its opening. Immediately preceding this slow climatic deterioration is the time with the warmest global temperatures of the past 85 million years, the protracted greenhouse episode known as the Early Eocene Climatic Optimum (EECO; 52$50 \mathrm{Ma}$; Zachos et al., 2001a). Whereas it is generally believed that a decline in atmospheric greenhouse gas concentrations terminated the EECO, compelling direct and unequivocal proxy evidence for this is generally lacking.

As a contrasting hypothesis, Bijl et al. (2013) find evidence for the first signs of throughflow of south-west (SW) Pa- cific surface waters into the Australo-Antarctic gulf (AAG) across the Tasman Gateway coinciding with the onset of regional surface water and continental Antarctic cooling of 2$4^{\circ}$. Bijl et al. (2013) infer from the distinct difference in dinocyst assemblages between the AAG and the SW Pacific that the Tasman Gateway served as an effective barrier to surface water exchange before 50 Ma. From 49-50 Ma onwards, endemic dinocyst species originating in the SW Pacific began to dominate sediments of the Antarctic margin of the AAG. They propose that the timing is consistent with the drowning of continental blocks in the southern part of the Tasman Gateway inferred from accelerated rifting during the early-to-middle Eocene transition (52-48 Ma; Close et al., 2009; Hill and Exon, 2004). Surface water throughflow of SW Pacific surface waters into the AAG would bring the endemic Antarctic species into the AAG. A crucial observation here is that the south Australian margin remains isolated from the SW Pacific influence but remains exclusively inhabited by cosmopolitan and low-latitude-derived dinocyst species. Furthermore, the influence of surface water throughflow from the AAG into the south-west Pacific remains restricted as well: no low-latitude-derived species appear in the SW Pacific Ocean. Eastward flow through the Tasman Gateway would be expected to bring the low-latitude species from the Australian margin into the SW Pacific Ocean. This is contrary to their findings; therefore, they hypothesize that the throughflow must have occurred to the south, perhaps within the reach of the easterlies, allowing the throughflow of the taxa present in the Ross Sea that consistently dominate the westward flow along Antarctica, the Eocene Antarctic Counter Current.

Organic biomarker proxy records for the paleotemperature of the sea surface and for the air temperature were derived from the same sedimentary archives as the oceanographic reconstructions. They show that the opening of the Tasmanian Gateway coincided with surface water and air temperature cooling of several degrees $\left(2-4^{\circ} \mathrm{C}\right)$, with the Antarctic hinterland cooling the most $\left(4^{\circ} \mathrm{C}\right)$. Simultaneously, benthic foraminiferal oxygen isotope records show the onset of gradual cooling as well. Although this study could not prove causality between oceanographic changes and cooling, the closeness in time is intriguing and requires a follow-up to prove causality.

The uncertainty related to the role of gateways in longterm climate evolution, as well as the increasing need for more detailed knowledge of Cenozoic ocean current development in general, stimulates modelling studies on the impact of gateway changes on ocean circulation through time. Here, we will use a coupled climate model of intermediate complexity (Sijp et al., 2011) to numerically simulate the effect of an initial opening of the Tasman Gateway at the earlyto-middle Eocene transition. We show that this can lead to the inferred patterns (Bijl et al., 2013) of dinoflagellate biogeography: a westward current emerges, but only when the Drake Passage remains closed. Numerical modelling pro- 
vides a physical basis to explain micropalaeontological observations.

\section{Model and experimental design}

We use a modified version of the intermediate-complexity coupled model described in detail in Weaver et al. (2001), the so-called UVic (University of Victoria) model. The model consists of an ocean general circulation model (GFDL MOM, Geophysical Fluid Dynamics Laboratory Modular Ocean Model, Version 2.2; Pacanowski, 1995) coupled to a simplified one-layer energy-moisture balance model for the atmosphere and a dynamic-thermodynamic sea-ice model. Air-sea heat and freshwater fluxes evolve freely in the model, while a non-interactive wind field is employed for reasons of computational speed. The turbulent kinetic energy scheme of Blanke and Delecluse (1993) based on Gaspar et al. (1990) models vertical mixing due to wind and vertical velocity shear. The model is identical to Sijp et al. (2011), with a modification to the Eocene geography in the primary experiments where Australia is located further south by $6^{\circ}$ in latitude and the Antarctic margin facing it is also shifted south.

The original geography will also be discussed as a secondary set of experiments in the sensitivity study below, where both geography is altered and the Southern Hemisphere westerlies are shifted. Motivation for these sensitivity studies of the true paleolatitude of the Tasman Gateway arises as comparisons of Eocene palaeogeographies may vary by about $6^{\circ}$ in the SW Pacific region dependent on which reference frame is used: a hotspot versus a paleomagnetic reference frame (van Hinsbergen et al., 2015).

We have run the model to equilibrium for a period of 9000 years in four configurations in which the Drake Passage is open to $517 \mathrm{~m}$ depth and in simulations where it is closed; in each case the Tasman Gateway is open, to a shallow depth of around $350 \mathrm{~m}$, and closed. This choice is informed by the expectation that the state of the Drake Passage exerts a strong influence on the result of the opening of the Tasman Gateway: the uncertainty surrounding the timing of the opening of the Drake Passage (see, e.g., Lagabrielle et al., 2009) makes it necessary for us to consider an open and a closed case.

Limitations arise from the absence of a fully coupled ocean and atmosphere in the UVic model. However, this model allows high enough spatial resolution to represent the shallow, southern opening of the Tasmanian Gateway during the early Eocene combined with long enough integration times to equilibrate the deep ocean to examine a possible global temperature signal. Furthermore, it provides the flexibility to conduct many simulations at once, each representing different scenarios. To provide backup for the realistic set-up of our model and cover both uncertainty in the location of the wind fields and their possible changes, our study prominently features experiments where the winds have been shifted, precisely to test the robustness of the results and
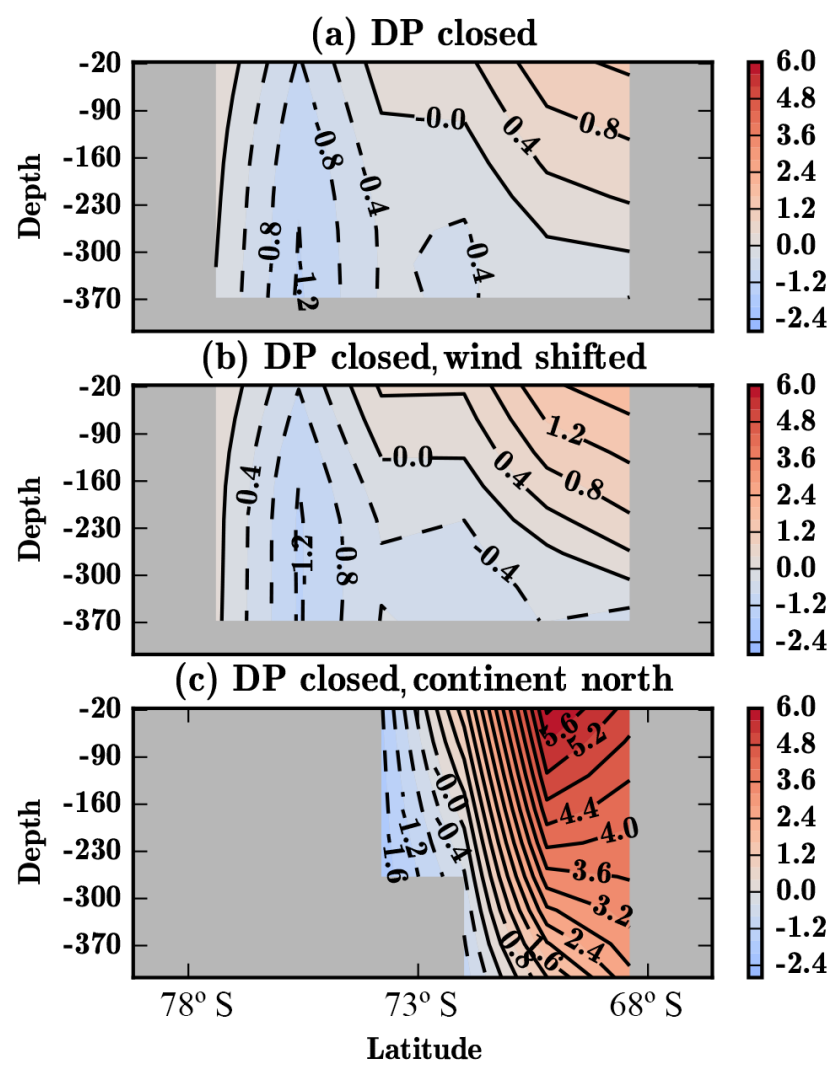

Figure 1. Meridional section of zonal velocity $u\left(\mathrm{~cm} \mathrm{~s}^{-1}\right)$ inside the Tasman Gateway with the Drake Passage closed for (a) the standard simulation, (b) the Southern Hemisphere westerlies shifted $6^{\circ}$ northward, and (c) Australia and the Antarctic margin in a more northward position. All locations are well south of the latitudes of zero wind stress curl. Positive values indicate eastward flow; negative values indicate westward flow.

cover the changes a fully coupled system might exhibit. Furthermore, a simulation with an alternative wind field is explored in the Appendix. Nonetheless, there could potentially be benefits to examining first-order geostrophic feedbacks on the wind, an option that is present in the UVic model.

\section{Results}

The latitudinal section of the zonal velocity through the TG gap for the DP-closed case is shown in Fig. 1a and for the DP-open case in Fig. 2a. In the simulation with the southern Tasman Gateway open, a closed DP leads to a westward flow throughout the water column near Antarctica and a shallower eastward flow to the north (Fig. 1a). In contrast, the flow is eastward throughout the gap when the DP is open (Fig. 2a). In this simulation, the eastward flow is weak throughout most of the gap but strong at its northern margin.

To examine the sensitivity of these results to boundary conditions, we conducted two additional simulations where the core of the Southern Hemisphere $(\mathrm{SH})$ westerlies is 
(a) DP open

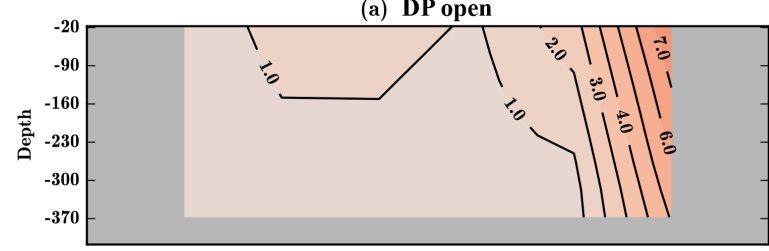

(b) DP open, wind shifted

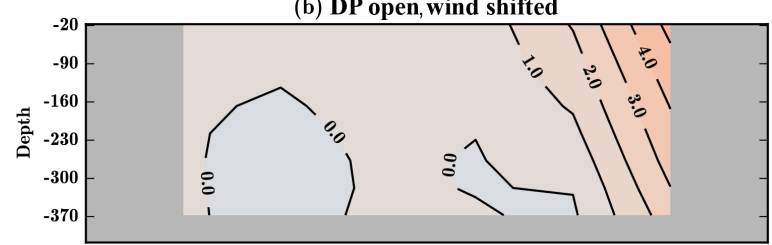

(c) DP open, continent north

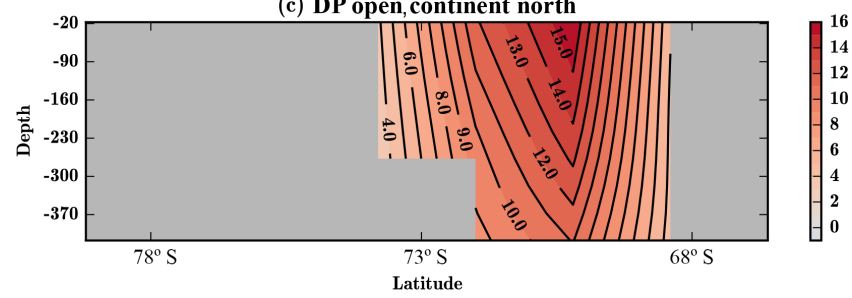

Figure 2. Meridional section of zonal velocity $u\left(\mathrm{~cm} \mathrm{~s}^{-1}\right)$ inside the Tasman Gateway with the Drake Passage open for (a) the standard simulation, (b) the Southern Hemisphere westerlies shifted $6^{\circ}$ northward, and (c) Australia and the Antarctic margin in a more northward position. All locations are well south of the latitudes of zero wind stress curl.

shifted $6^{\circ}$ north, the TG is open, and the DP is open and closed (thus yielding two simulations). For reference, we show the zonal wind stress overlaid on the horizontal stream function in Fig. 3: the average latitude of maximum westerly wind stress (zero wind stress curl) is $5^{\circ} \mathrm{S}$ in the standard case and $44^{\circ} \mathrm{S}$ latitude in the wind-shifted case. This wind shifting procedure is essentially equivalent to Sijp and England (2009), and we refer to this work for reference. We will refer to the original simulations without the modification as the "standard" case. In this modified model configuration, the flow pattern (Fig. 1b) is very similar to the standard case with the DP closed (Fig. 1a). Similarly, in the DP-open case, the flow pattern remains easterly throughout the TG gap, again with weak flow through most of the gap, with the exception of the northern margin (Fig. 2b). Note that, in contrast to the corresponding standard simulation (Fig. 2a), there is weak westward flow in a very narrow band below $250 \mathrm{~m}$ depth; nonetheless, the general flow is overwhelmingly eastward.

In addition, we also conducted two simulations, again with the TG open and the DP open and closed but now with altered geography. Here, the Australian continent is shifted north by $6^{\circ}$ latitude with respect to our standard simulation, along with some northward shift of the Antarctic margin of the AAG (thus obtaining the original geography used in Sijp et al., 2011). A southward-extending peninsula is also attached at the location of Tasmania, in agreement with Bijl

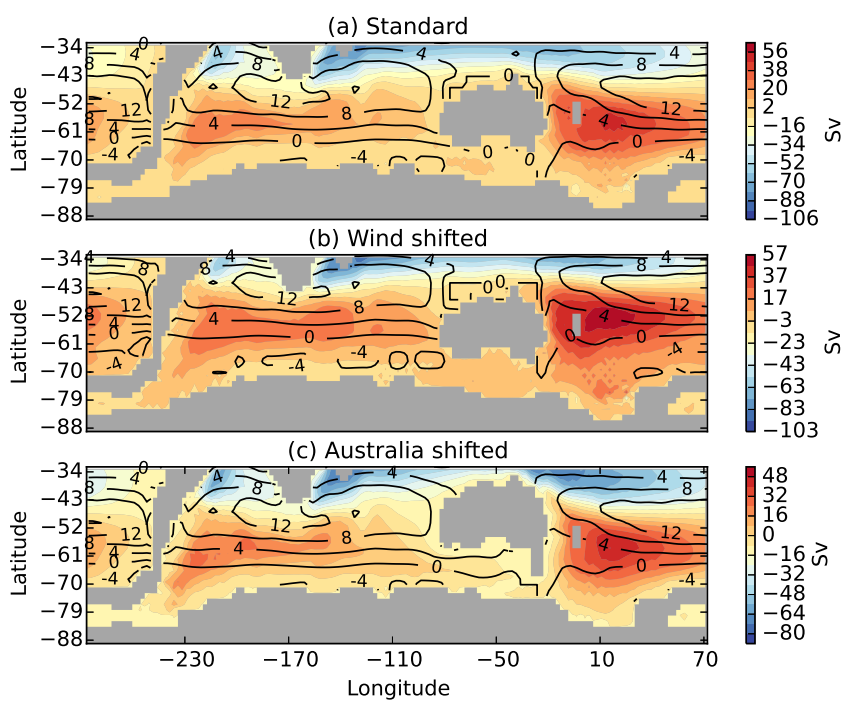

Figure 3. Ocean horizontal stream function (Sverdrup; $1 \mathrm{~Sv}$ is $\left.10^{6} \mathrm{~m}^{3} \mathrm{~s}^{-1}\right)$, with the zonal wind stress $\left(10^{6} \mathrm{~Pa}\right)$ overlaid. The Drake Passage is closed for (a) the standard simulation, (b) the Southern Hemisphere westerlies shifted north, and (c) Australia and part of the Antarctic coast shifted north.

et al. (2013). Again, a similar flow pattern emerges, where flow is eastward throughout the TG gap in the DP-open case (Fig. 2c), while there is a westward current near Antarctica in the DP-closed case (Fig. 1c). We conclude from our four additional simulations that our results are robust with respect to the location of the major wind circulation patterns and geography.

From here on, we will focus on the standard simulations. First, we examine the oceanic horizontal circulation. With the DP closed, the circulation of the Southern Ocean is split into two subpolar clockwise gyres, the Ross Sea gyre to the east of Australia and the Weddell gyre spanning the (south) Indian and Atlantic oceans to the east of the DP. To the north lie the subtropical gyres, where a super-gyre spans the Indian and Pacific oceans. In agreement with the Sverdrup balance, eastward flow takes place at the latitudes of positive wind stress curl (approximately minus the latitudinal derivative of the wind stress shown in Fig. 3). A proto-ACC is absent due to the closure of the DP. Practically all eastward flow that passes Australia does so to the north of the continent and is part of the southern branch of the subtropical super-gyre.

Eastward flow in the northern branches of the subpolar gyres generally ends by returning south along the western margins of Australia and South America when the DP is closed (Fig. 1a). A discussion of the possibility of a linkage between the two subpolar gyres, using additional simulations with another model, can be found in Appendix A. Although the barotropic stream function shows no flow at the selected contour interval, the velocity field indicates a westward flow in the Tasman Gateway closely restricted to the Antarctic 
margin, naturally consistent with Fig. 1a. This westward flow through the TG is consistent with the generally negative wind stress curl at these latitudes.

An open DP under otherwise early Eocene boundary conditions yields around $35 \mathrm{~Sv}$ flow through this gap, as read from the $5 \mathrm{~Sv}$ interval contours immediately west of the DP (Fig 4a) and as determined by closer analysis on the computer of the numerical model output (figure not shown). The $35 \mathrm{~Sv}$ throughflow at the DP leads to eastward flow through the TG of around $8 \mathrm{~Sv}$ as determined from the model output file by computer analysis and shown less precisely in Fig 4a. The remaining $27 \mathrm{~Sv}$ must pass north of Australia. This total of $35 \mathrm{~Sv}$ of flow constitutes a circumpolar flow component that is not part of the gyre structure and is reminiscent of the ACC, despite the lack of latitudinal alignment of the gateways. We stress that this flow is much weaker than today and not comparable, even qualitatively. Nonetheless, we will refer to this current as the "proto-ACC". As such, the uniformly eastward flow through the TG can be viewed as a consequence of the flow through the DP gap that joins the eastward flow along the northern branch of the Weddell gyre that must split to flow around Australia, yielding a southern component. In addition, when opening the Drake Passage, there is less necessity for significant westward return flow in the subpolar gyres. Indeed, high-resolution ocean model simulations have shown that closing the DP forces the ACC water to mainly turn southwards and join the subpolar gyres (unpublished results). The circumpolar flow is in line with idealized ocean modelling studies suggesting that strong circumpolar flow is possible even without a fully unrestricted latitude band (Munday et al., 2015). This eastward flow occurs entirely within the latitudes of the polar easterlies in the model (Fig. 3) and within the latitudes of negative wind stress curl (with a small exception in the wind-shifted case). This shows that the direction of the flow is not only determined by the wind field but also by the continental geometry.

\section{Dinoflagellate biogeography and ocean circulation}

To examine links between Eocene ocean circulation and dinoflagellate biogeography, we conduct several decadal timescale simulations, starting from model equilibria, where a passive tracer (i.e. not interacting with the ocean flow and representing small entities that do not move of their own accord) is released at two locations, one south-east and one west of Australia. We assume here that the current velocities of the surface water dominate the active swim velocities of the dinoflagellates themselves. In any case, surface sediment analyses in the North Atlantic show a clear dominance of specific Gulf Stream-loving dinocysts within the pathway of the Gulf Stream (e.g. Zonneveld et al., 2013), confirming the strong governance by oceanography of biogeography of dinocyst species.
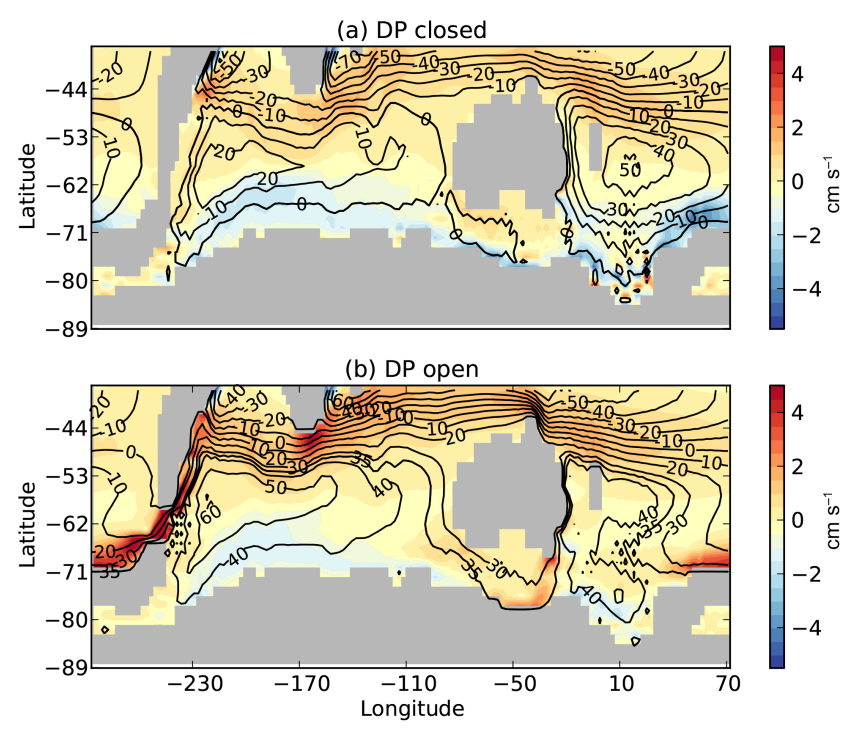

Figure 4. Annual and vertical average of zonal velocity $\left(\mathrm{cm} \mathrm{s}^{-1}\right.$; positive values indicate eastward flow) with ocean horizontal stream function (Sverdrup; $1 \mathrm{~Sv}$ is $10^{6} \mathrm{~m}^{3} \mathrm{~s}^{-1}$ ) overlaid. The Tasman Gateway is open, with (a) the Drake Passage (DP) closed and (b) the DP open (shallow at around $350 \mathrm{~m}$ depth). Contour intervals have been adjusted in (a) to elucidate the flow through the TG.

Again, we perform two sets of simulations: a first set with the DP closed and open or closed TG and a second set where the DP is open and the TG is open or closed. The results of the tracer simulations are shown in Figs. 5 and 6, where the sites of the release of the tracer are marked by an ellipse. We examine a snapshot taken 5 years after tracer release. The tracer is interpreted as a fractional dinoflagellate concentration, and its subsequent dispersal allows an estimate of expected dinoflagellate biogeography based on ocean flow alone. The initial condition consists of the instantaneous insertion of a (rotationally symmetric) Gaussian distribution of tracer in the horizontal direction of amplitude 1 (the tracer concentration is close to fraction 1 , or $100 \%$, at the core of the anomaly) and a horizontal standard deviation of several model grid cells, allowing tracer concentration to approach zero away from the core and similarly rapidly decreasing concentrations with depth according to a smaller standard deviation appropriate to the vertical scale.

First, we examine four simulations where the DP remains closed. Perhaps as might be expected, unable to cross the TG and lacking alternative routes, tracer "species" remain on the side of the TG where they were released when the TG remains closed (Fig. 5a, b). However, when the TG is open, tracer species released from the west of Australia (Fig. 5c) enter the AAG along the Australian coast but do not proceed into the Ross Sea, east of the open TG. Instead, concentrations are focussed along the Antarctic coast in the South Atlantic (and west of the AAG). This is due to the westward flow along Antarctica there and in the AAG (Figs. 1 and 4). 

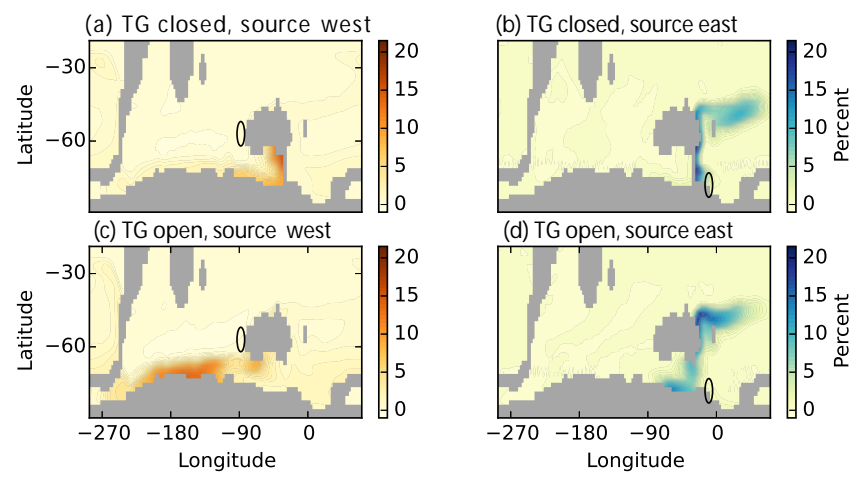

Figure 5. Dispersal of passive tracer representing dinoflagellates for the Drake Passage closed and for the Tasman Gateway (TG) closed, originating west (a) and east (b) of Australia, and for TG open, originating west (c) and east (d) of Australia. Circles indicate the release sites. When the TG is open, dinoflagellates released to the west of Australia enter the Australo-Antarctic Gulf predominantly along the Australian coast but remain west of the TG and do not enter the Ross Sea (c). In contrast, species released near the Ross Sea may enter the gulf via a westward flow along the Antarctic coast (d). Concentrations are in percentages, where the initial localized concentration upon release was $100 \%$. We examine a snapshot taken 5 years after tracer release.

Westward propagation along the Antarctic coast of dinoflagellate tracer released east of the TG in the open-TG configuration is evidenced by the local maximum in tracer concentration along the Antarctic coast of the AAG in Fig. 5d. This is also because of the westward flow through the TG (Fig. 4). The biogeography that can be inferred from our results is in agreement with Bijl et al. (2013), who infer that lower-latitude taxa that are abundant to the west of Australia remain geographically constrained to the west of the TG after the southerly opening of the Tasman Gateway. Notably the consistency in the simulated biogeographic patterns inferred from the model is unrelated to the regional environmental differences (e.g. temperature) and only the result of current vectors distributing the dinocysts in the region. This absence of a relationship between environmental factors and biogeography is particularly convenient since Bijl et al. (2011) also showed that the onset of regional dominance of endemic dinocysts in the SW Pacific Ocean was unrelated to surface water temperature. Also in agreement with field evidence (Bijl et al., 2013) is the westward propagation of SW Pacific tracer species into the AAG in response to gateway opening and the restriction of that propagation to the Antarctic coast of the AAG.

Second, to elucidate the role of the DP in our dinoflagellate tracer results, we performed versions of the second set of tracer simulations described above where the DP is now consistently open (Fig. 6). Similarly to the DP-closed scenario and perhaps trivially, when the DP is open and the TG remains closed, species released at both sides of the TG land bridge remain on their corresponding side of that land bridge
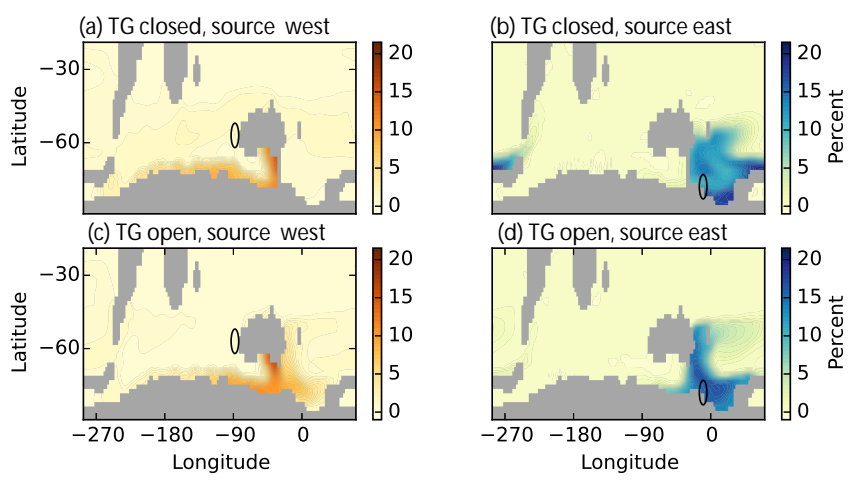

Figure 6. As Fig. 5, but for the Drake Passage open. When the Tasman Gateway (TG) is open, dinoflagellates released to the west of Australia enter the Australo-Antarctic Gulf and flow into the Ross Sea through the TG (c). Species released near the Ross Sea may enter the gulf along the Antarctic coast (d). We examine a snapshot taken 5 years after tracer release.

(Fig. 6a, b), although very small concentrations penetrate north of Australia via flow through the open DP. When the TG is open, tracer released to the west of Australia (Fig. 6c) enters the AAG. However, unlike the DP-closed case, tracer now penetrates well into the Ross Sea. This is because of the eastward flow through the open TG that is part of a protoACC flowing through the open DP (Figs. 2 and 4). This effect is in strong disagreement with field evidence, as dinocyst assemblages in the SW Pacific only show a low-latitude affinity when the Tasmanian Gateway deepens at $35.5 \mathrm{Ma}$ and not earlier.

Some westward propagation along the Antarctic coast of dinoflagellate tracer released east of the TG in the open-TG configuration is evidenced by the low but discernible tracer concentrations along the Antarctic coast of the AAG (Fig. 6d, compare to Fig. 5d: note the smaller scale in the latter), while most of the tracer flows north, along the east coast of Australia, in the Ross Sea gyre. In conclusion, the tracer dispersion patterns in the DP-open case are not in agreement with Bijl et al. (2013), as significant amounts of tracer released west of Australia penetrate into the SW Pacific upon the opening of the TG. This indicates that either the DP was closed during this period or sufficient obstructions existed downstream of the DP to prevent an eastward flow through the TG.

\section{Temperature changes in response to gateway opening.}

The opening of the TG in our model configuration where the DP remains closed leads to no significant sea surface temperature cooling (Fig. 7). This is in contrast to the hypothesis of Bijl et al. (2013) that the cooling seen in their field evidence of surface water and regional air temperature reconstructions is a direct result of gateway changes and the ensuing changes in ocean currents. Furthermore, none of our 

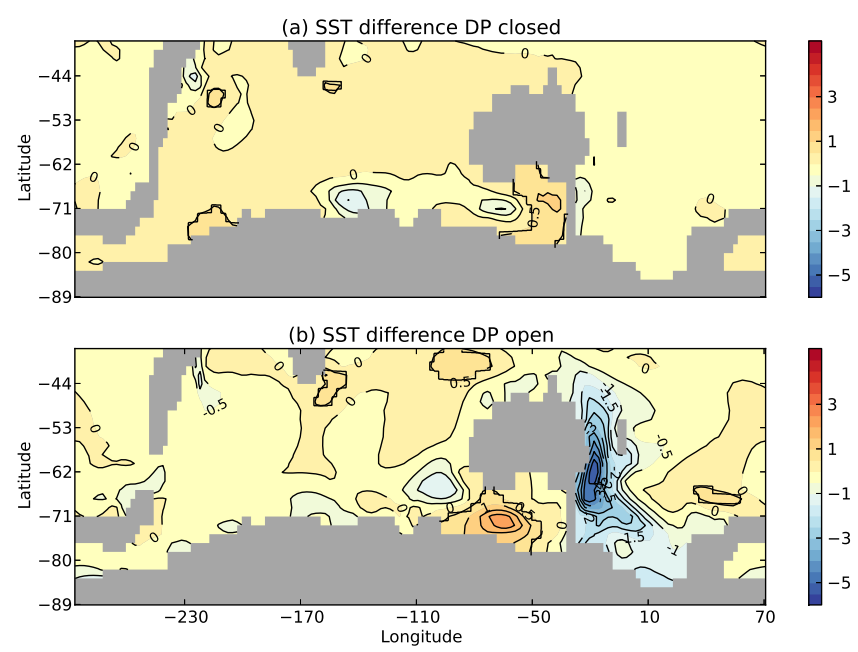

Figure 7. Sea surface temperature change in response to opening the Tasman Gateway (TG). Difference between TG open and TG closed for (a) the Drake Passage (DP) closed and (b) the DP open during the opening of the TG. The opening of the TG leads to a maximum of around $4.0^{\circ} \mathrm{C}$ localized surface ocean cooling to the east of Australia only when the DP is open.

experiments show significant deep- or mid-ocean cooling. We suggest that future climate modelling work could shed further light on the relationship between Antarctic temperature changes and the gateway changes. Sea surface temperatures close to Antarctica have similar values of 10 to $12{ }^{\circ} \mathrm{C}$ on both sides of the TG when the TG is closed and the DP is open or closed (Fig. 8). As a result, although a westward flow emerges from the Ross Sea to the AAG (see above), the opening of the TG in our model configuration where the DP remains closed leads to no significant sea surface temperature cooling (Fig. 7).

\section{Summary and conclusions}

Our model results provide a numerical underpinning of the recent field observations and interpretations of Bijl et al. (2013) that a southerly opening of the Tasman Gateway causes throughflow of SW Pacific surface waters into the AAG. For the first time, we reproduce a westward propagation of oceanic properties and species originating east of the Tasman Gateway upon its early opening, leading to the introduction of endemic dinocyst species originating in the SW Pacific into the southern margin of the AAG but not the northern margin. This is consistent with our finding that the westward current is restricted to the southern margin of the AAG. Also consistent with micropalaeontological observations, no low-latitude-derived species (released west of Australia in our simulations) could be routed via the TG to appear in the SW Pacific Ocean upon its opening.

Importantly, our model results indicate that the waters of the DP, or upstream or downstream areas close to it, are likely (a) SST TG closed DP closed

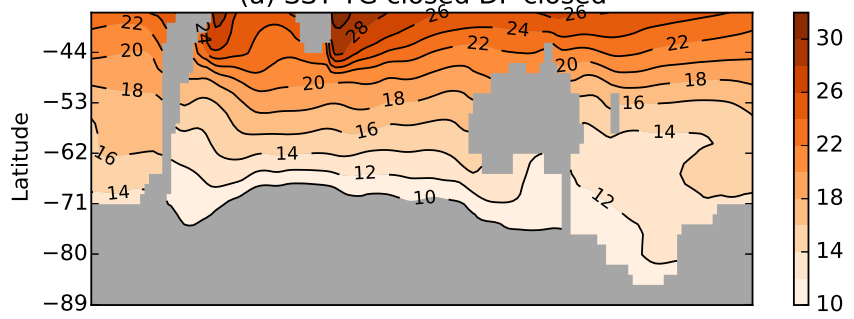

(b) SST TG closed DP open

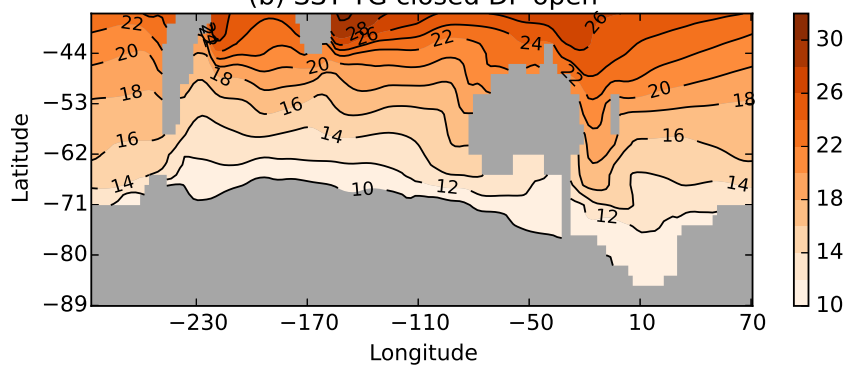

Figure 8. Sea surface temperature for (a) the Drake Passage (DP) closed and (b) the DP open.

to have been obstructed by large-scale geostrophic flow during the early Eocene, as the passive tracer experiments in a scenario with a closed DP are much more consistent with microfossil evidence compared to a scenario with an open DP. Lagabrielle et al. (2009), Ghiglione et al. (2008), Eagles (2003), Livermore et al. (2005), Eagles et al. (2005), and Livermore et al. (2007) infer a progressive opening of the Drake Passage, through continental extensional tectonics and oceanic spreading (Eagles et al., 2006), after about $50 \mathrm{Ma}$ from the analysis of seafloor magnetic anomalies in the Scotia Sea and adjoining oceanic areas. This timing suggests that the DP may have been sufficiently obstructed to prevent an ACC.

Our results, and those of (Bijl et al., 2013), indicate a later opening of the DP. Alternative to the DP closure, we raise the question (for future research) of whether a similar effect could have been achieved from severe obstructions to a wide and deep flow through the DP and nearby areas at similar latitudes, a possibility not explored in our model experiments. For instance, model results by Hill et al. (2013) indicate that, regardless of the state of the DP and TG, a coherent ACC was not possible during, for instance, the Oligocene (a period much later than that under study here) due to the Australasian palaeogeography, although no inferences are made for the Eocene. Future work on these obstructions is therefore important. Finally, our numerical study is not consistent with the idea that such an oceanographic change can cause a significant and uniform Antarctic cooling. Nonetheless, our result of a westward current made possible by a restriction of the ACC away from the TG region provides an ocean dynamics background to the finding of Bijl et al. (2013) and other studies that point to this current. 


\section{Appendix A: Dependence on model and geometry}

As the position of Australia plays an important role in whether the subtropical and subpolar gyres of the Indian and Pacific oceans pass that continent northward or southward, we performed additional simulations with (i) another ocean model and (ii) a different reconstruction of the continental geometry. We use the Parallel Ocean Program (POP) developed at Los Alamos Laboratory Dukowicz and Smith (1994) at a nominal horizontal resolution of $1^{\circ} \times 1^{\circ}$ and 40 vertical levels. The model was adapted to a late Eocene reconstruction of the continental geometry and bathymetry Rugenstein et al. (2014) and forced with the atmospheric state of a coupled climate model simulation using the Community Earth System Model (CESM; Goldner et al., 2014). Compared to the continental geometry in the UVic simulations of the main paper, Australia extends substantially further north in this configuration as it represents the late Eocene or early Oligocene rather than the middle Eocene. The model is run for 570 years in two configurations: the late Eocene control case, where the Tasman gateway is open and the Drake Passage is almost closed (35 m deep) and a second case where a land bridge is built in the Tasman gateway from Tasmania to Antarctica. The throughflow through the Drake Passage is very small, so we can consider the DP closed in these simulations. We show results averaged over the last 10 years of simulation.
Figure A1 shows the vertically averaged zonal velocity for the two cases, with contours of sea surface height (SSH) overlaid. The SSH can be regarded as similar to the barotropic stream function as it represents the barotropic flow. In general, the POP simulations show very similar features to the (coarser) UVic simulations shown in the main part of the paper. The model is forced by the same wind pattern as the UVic simulations, and in particular, the Tasman Gateway is entirely in the latitudes of the polar easterlies. However, in the POP simulations, Australia is located further north and, therefore, effectively blocking the eastward flow at the boundary between the subtropical and subpolar gyres. As a result, less flow passes north of Australia from the Indian to the Pacific Ocean, but a substantial part of this flow also passes south of Australia, thereby inducing considerable eastward flow in the Tasman gateway when open (Fig. A1b). In a vertical section through the Tasman gateway (Fig. A2), this becomes evident as a strong and deep-reaching eastward current in the central northern part of the gateway, while a weak westward current at the Antarctic margin remains. This gives further support to the notion that, if the DP is sufficiently obstructed, the eastward flow at the boundary between the subtropical and subpolar gyres returns mostly in the subpolar gyres, i.e. along the Antarctic margin. 
(a)

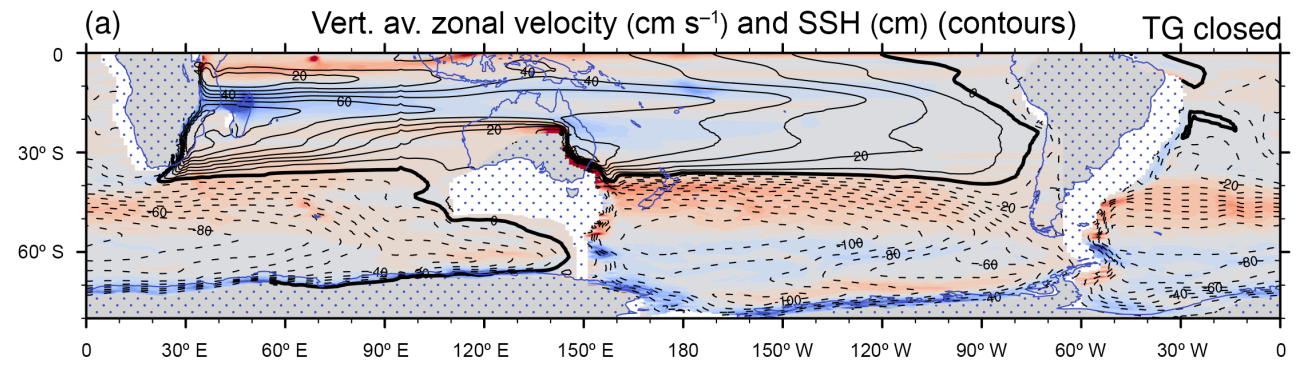

(b)

Vert. av. zonal velocity $\left(\mathrm{cm} \mathrm{s}^{-1}\right)$ and $\mathrm{SSH}(\mathrm{cm})$ (contours)
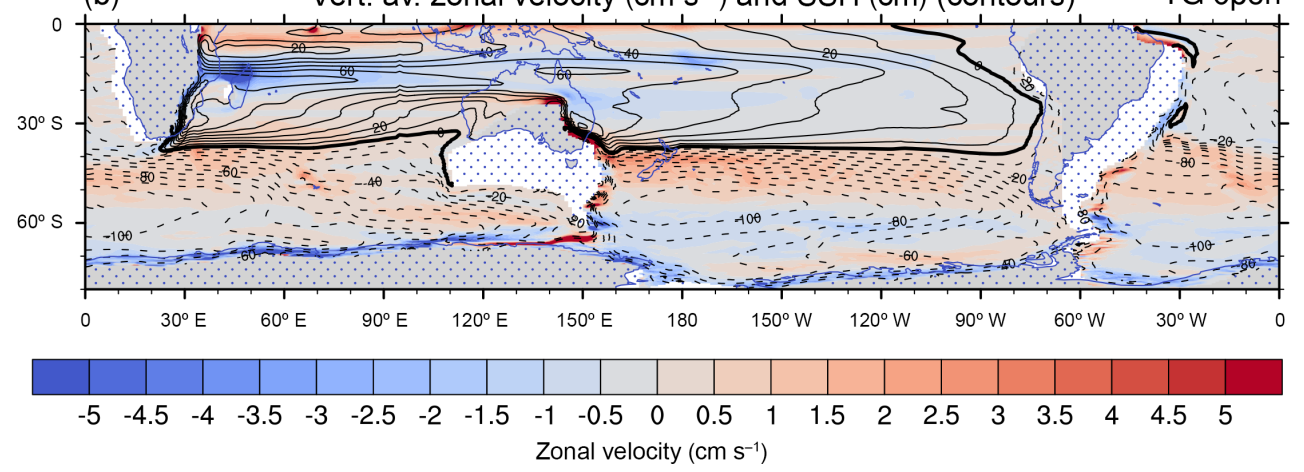

Figure A1. Annual and vertical average zonal velocity $\left(\mathrm{cm} \mathrm{s}^{-1}\right.$; positive values indicate eastward flow) with contours of sea surface height (SSH in $\mathrm{cm}$ ) overlaid for the late Eocene simulation using a different ocean model (POP), with the Tasman Gateway (TG) closed (a) and open (b). The Drake Passage is shallower than $35 \mathrm{~m}$ in these simulations and can be considered closed.

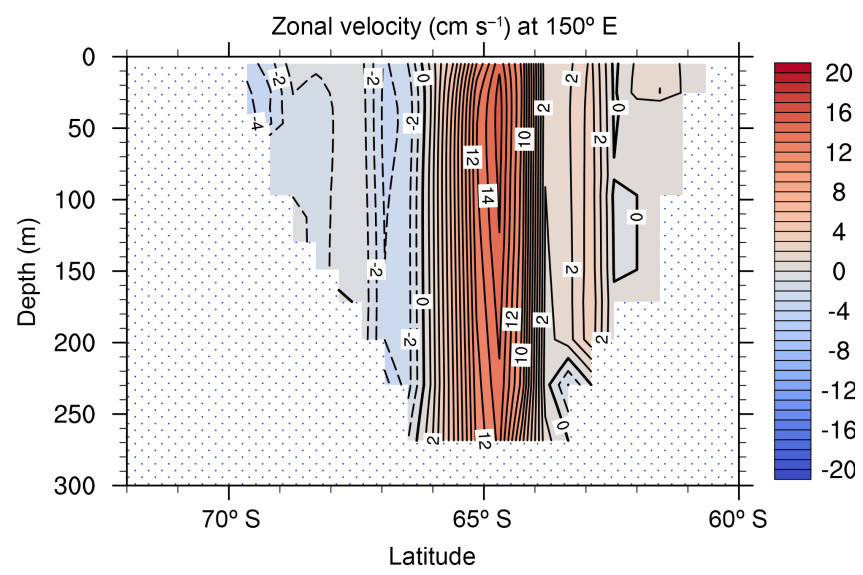

Figure A2. Meridional section of zonal velocity $u\left(\mathrm{~cm} \mathrm{~s}^{-1}\right)$ inside the Tasman Gateway for the late Eocene POP simulation. 
Acknowledgements. We thank the University of Victoria staff for support in usage of the their coupled climate model. This research was supported by the Australian Research Council (ARC). This work contributes to ARC project DP1096144 held by Willem P. Sijp and ALW 802.01.024 of the Netherlands Organization for Scientific Research (NWO), Earth and Life Sciences held by Anna S. von der Heydt. The POP computations were done on the Cartesius computer at SURFsara in Amsterdam. The use of the SURFsara computing facilities was sponsored by NWO under the project SH-209-14. Peter K. Bijl acknowledges NWO-ALW for VENI grant number 863.13.002. Figures were produced with the Spacegrids Python data analysis module.

Edited by: A. Paul

\section{References}

Barker, P. F. and Burrell, J.: The opening of Drake Passage, Mar. Geol., 25, 15-34, 1977.

Barrett, P. J.: Antarctic paleoenvironment through Cenozoic times a review, Terra Ant., 3, 103-119, 1996.

Beerling, D. J. and Royer, D. L.: Convergent Cenozoic $\mathrm{CO}_{2}$ history, Nat. Geosci., 4, 418-420, 2011.

Bijl, P. K., S. Schouten, S., and Sluijs, A.: Early Palaeogene temperature evolution of the Southwest Pacific Ocean, Nature, 461, 776-779, 2009.

Bijl, P. K., Pross, J., Warnaar, J., Stickley, C. E., Huber, M., Guerstein, R., Houben, A. J. P., Sluijs, A., Visscher, H., and Brinkhuis, H.: Environmental forcings of Paleogene Southern Ocean dinoflagellate biogeography, Paleoceanography, 26, PA1202, doi:10.1029/2009PA001905, 2011.

Bijl, P. K., Bendle, J. A. P., Bohaty, S. M., Pross, J., Schouten, S., Tauxe, L., Stickley, C. E., McKay, R. M., Roehl, U., Olney, M., Sluijs, A., Escutia, C., Brinkhuis, H., and Expedition 318 Scientists: Eocene cooling linked to early flow across the Tasmanian Gateway, PNAS, 10, 9645-9650, 2013.

Blanke, B. and Delecluse, P.: Variability of the tropical Atlantic Ocean simulated by a general circulation model with two different mixed-layer physics, J. Phys. Oceanogr., 23, 1363-1388, 1993.

Cande, S. C. and Stock, J. M.: Pacific-Antarctic-Australia motion and the formation of the Macquarie Plate, Geophys. J. Int., 157, 399-414, 2004.

Close, D. I., Watts, A. B., and Stagg, H. M. J.: A marine geophysical study of the Wilkes Land rifted continental margin, Antarctica, Geophys. J. Int., 177, 430-450, 2009.

DeConto, R. M. and Pollard, D.: Rapid Cenozoic glaciation of Antarctica induced by declining atmospheric $\mathrm{CO}_{2}$, Nature, 421, 245-248, 2003.

DeConto, R. M., Pollard, D., Wilson, P. A., Paelike, H., Lear, C. H., and Pagani, M.: Thresholds for Cenozoic bipolar glaciation, Nature, 455, 652-656, 2008.

Dukowicz, J. K. and Smith, R. D.: Implicit free-surface method for the Bryan-Cox-Semtner ocean model, J. Geophys. Res., 99, 7991-8014, 1994.

Eagles, G.: Plate tectonics of the Antarctic-Phoenix plate system since 15 Ma, Earth Planet. Sci. Lett., 88, 289-307, 2003.
Eagles, G., Livermore, R. A., Fairhead, J. D., and Morris, P.: Tectonic evolution of the west Scotia Sea, J. Geophys. Res., 110, B02401, doi:10.1029/2004JB003154, 2005.

Eagles, G., Livermore, R. A., and Morris, P.: Small basins in the Scotia Sea: the Eocene Drake Passage gateway, Earth Planet. Sci. Lett., 242, 343-353, 2006.

Gaspar, P., Gregoris, Y., and Lefevre, J. M.: A simple eddy kinetic energy model for simulations of the oceanic vertical mixing: Tests at station PAPA and long-term upper ocean study site, J. Geophys. Res., 95, 16179-16193, 1990.

Ghiglione, M. C., Yagupsky, D., Ghidella, M., and Ramos, V. A.: Continental stretching preceding the opening of the Drake Passage: Evidence from Tierra del Fuego, Geology, 36, 643-646, 2008.

Goldner, A., Herold, N., and Huber, M.: Antarctic glaciation caused ocean circulation changes at the Eocene-Oligocene transition, Nature, 511, 574-577, doi:10.1038/nature13597, 2014.

Hill, D. J., Haywood, A. M., Valdes, P. J., Francis, J. E., Lunt, D. J., Wade, B. S., and Bowman, V. C.: Paleogeographic controls on the onset of the Antarctic circumpolar current, Geophys. Res. Lett., 40, 5199-5204, 2013.

Hill, P. J. and Exon, N. F.: The Cenozoic Southern Ocean: Tectonics, Sedimentation and Climate Change Between Australia and Antarctica, chap. 10, 151, American Geophysical Union, Washington, DC, 19-42, 2004.

Huber, M. and Sloan, L. C.: Heat transport, deep waters and thermal gradients:Coupled simulation of an Eocene "greenhouse" climate, Geophys. Res. Lett., 28, 3481-3484, 2001.

Huber, M., Brinkhuis, H., Stickley, C. E., Doos, K., Sluijs, A., Warnaar, J., Schellenberg, S. A., and Williams, G. L.: Eocene circulation of the Southern Ocean: was Antarctica kept warm by subtropical waters?, Paleoceanography, 19, PA4026, doi:10.1029/ 2004PA001,014, 2004.

Kennett, J. P.: Cenozoic evolution of Antarctic glaciation, the Circum Antarctic Ocean, and their impact on global paleoceanography, J. Geophys. Re., 82, 3843-3860, 1977.

Kennett, J. P. and Shackleton, N. J.: Oxygen isotopic evidence for development of psychrosphere $38 \mathrm{Myr}$ ago, Nature, 260, 513515, 1976.

Lagabriellea, Y., Goddéris, Y., Donnadieu, Y., Malavieille, J., and Suarez, M.: The tectonic history of Drake Passage and its possible impacts on global climate, Earth Planet. Sc. Lett., 279, 197211, 2009.

Livermore, R., Eagles, R., Morris, G., and Maldonado, P. A.: Shackleton fracture zone: no barrier to early circumpolar circulation, Geology, 32, 797-800, 2004.

Livermore, R., Nankivell, A., Eagles, G., and Morris, P.: Paleogene opening of Drake Passage, Earth Planet. Sc. Lett., 236, 459-470, 2005.

Livermore, R., Hillenbrand, C., Meredith, M., and Eagles, G.: Drake Passage and Cenozoic climate: An open and shut case?, Geochem. Geophy. Geosy., 8, Q01005, doi:10.1029/2005GC001224, 2007.

Munday, D. R., Johnson, H. L., and Marshall, D. P.: The role of ocean gateways in the dynamics and sensitivity to wind stress of the early Antarctic Circumpolar Current, Paleoceanography, 30, 284-302, doi:10.1002/2014PA002675, 2015. 
Pacanowski, R.: MOM2 Documentation User's Guide and Reference Manual: GFDL Ocean Group Technical Report 3, NOAA, GFDL. Princeton, 3 Edn., 232 pp., 1995.

Pagani, M., Zachos, J. C., Freeman, K. H., Tripple, B., and Bohaty, S.: Marked decline in atmospheric carbon dioxide concentrations during the Paleogene, Science, 309, 600-603, 2005.

Pearson, P. N., Foster, G. L., and Wade, B. S.: Atmospheric carbon dioxide through the Eocene-Oligocene climate transition, Nature, 461, 1110-1113, 2009.

Pfuhl, H. A. and McCave, I. N.: Evidence for late Oligocene establishment of the Antarctic Circumpolar Current, Earth Planet. Sc. Lett., 235, 715-728, 2005.

Rugenstein, M. A. A., Stocchi, P., von der Heydt, A. S., Dijkstra, H. A., and Brinkhuis, H.: Emplacement of Antarctic ice sheet mass affects circumpolar ocean flow, Global Planet. Change, 118, 16-24, 2014.

Scher, H. D. and Martin, E. E.: Timing and climatic consequences of the opening of Drake Passage, Science, 312, 428-430, 2006.

Sijp, W. P. and England, M. H.: Effect of the Drake Passage throughflow on global climate, J. Phys. Oceanogr., 34, 1254-1266, 2004.

Sijp, W. P. and England, M. H.: Southern Hemisphere Westerly Wind Control over the Ocean's Thermohaline Circulation, J. Climate, 22, 1277-1286, 2009.

Sijp, W. P., England, M. H., and Toggweiler, J. R.: Effect of ocean gateway changes under greenhouse warmth, J. Climate, 22, 6639-6652, 2009.

Sijp, W. P., England, M. H., and Huber, M.: Effect of deepening of the Tasman Gateway on the global ocean, Paleoceanography, 26, PA4207, doi:10.1029/2011PA002143, 2011.

Sijp, W. P., von der Heydt, A. S., Dijkstra, H. A., Flögel, S., Douglas, P., and Bijl, P. K.: The role of ocean gateways on cooling climate on long time scales, Global Planet. Change, 119, 1-22, 2014.
Sloan, L. C., Walker, J. C. G., and Moore, T. C.: Possible role of oceanic heat transport in Early Eocene climate, Paleoceanography, 10, 347-356, 1995.

Stickley, C. E., Brinkhuis, H., Schellenberg, S. A., Sluijs, A., Röhl, U., Fuller, M., Grauert, M., Huber, M., Warnaar, J., and Williams, G. L.: Timing and nature of the deepening of the Tasmanian Gateway, Paleoceanography, 19, PA4027, doi:10.1029/2004PA001022, 2004.

Toggweiler, J. R. and Bjornsson, H.: Drake Passage and paleoclimate, J. Quaternary Sci., 15, 319-328, 2000.

van Hinsbergen, D. J. J., de Groot, L. V., and van Schaik, S. J.: A Paleolatitude Calculator for Paleoclimate Studies, PLOS One, 10, e0126946, doi:10.1371/journal.pone.0126946, 2015.

Weaver, A. J., Eby, M., Wiebe, E. C., Bitz, C. M., Duffy, P. B., Ewen, T. L., Fanning, A. F., Holland, M. M., MacFadyen, A., Matthews, H. D., Meissner, K. J., Saenko, O., Schmittner, A., Wang, H. X., and Yoshimori, M.: The UVic Earth System Climate Model: model description, climatology, and applications to past, present and future climates, Atmos. Ocean, 39, 1067-1109, 2001.

Yang, S., Galbraith, E., and Palter, J.: Coupled climate impacts of the Drake Passage and the Panama Seaway, Clim. Dynam., 43, 37-52, 2013.

Zachos, J. C., Pagani, M., Sloan, L., Thomas, E., and Billups, K.: Trends, rythms, and aberrations in global climate 65 Ma to present, Science, 292, 686-693, 2001a.

Zonneveld, K. A. F., Marret, F., and Versteegh, G. J. M.: Atlas of modern dinoflagellate cyst distribution based on 2405 datapoints, Rev. Palaeobot. Palyno., 191, 1-197, 2013. 